\title{
Rehabilitation of sucking and swallowing alterations in premature newborn at the Neonatal Intensive Care Unit
}

\author{
Edda Aguilar-Vázquez*, M. Lucía Pérez-Padilla, M. de Lourdes Martín-López and \\ Adriana Abigail Romero-Hernández \\ Departamento de Rehabilitación, Hospital Infantil de México Federico Gómez, Mexico City, Mexico
}

\begin{abstract}
Over the last 20 years, 640 premature newborns with suction-deglutition alterations have been taken care of in the Neonatal Intensive Care Unit (NICU) at the Hospital Infantil de Mexico Federico Gómez, using techniques for patients with immaturity and neurological, gastrointestinal, cardiologic and respiratory pathologies. This descriptive study includes the treatment employed mainly in premature newborns during this period. Suction, swallowing, and breathing coordination are some of the most complex abilities that premature newborns face due to their anatomic and functional immaturity and improper sensorimotor integration for the high energy requirements they must meet. Sucking and swallowing are voluntary and involuntary processes that guarantee the safe passage of food from the mouth to the stomach and require the coordination of the cranial nerves, the brain stem and cerebral cortex and muscles of the mouth, pharynx, and esophagus. The rehabilitation treatment consists in the positioning of the newborn and caretaker, adaptation of teats, regulation of muscle tone and progressive intake of milk. The feeding processing was reduced to 1.5 weeks in newborns submitted to the treatment, whereas in those who did not receive the treatment, the process took up to three weeks.
\end{abstract}

Key words: Sucking. Deglutition. Prematurity. Orthodontics. Suction. Breastfeeding.

\section{Rehabilitación de las alteraciones en la succión y deglución en recién nacidos prematuros de la Unidad de Cuidados Intensivos Neonatales}

\section{Resumen}

En 20 años se han atendido 640 recién nacidos prematuros (PNB) y recién nacidos a término con alteraciones en la coordinación de la succión-deglución en la Unidad de Cuidados Intensivos Neonatales (UCIN) del Hospital Infantil de México Federico Gómez, empleado técnicas de tratamiento para pacientes con inmadurez, patologías de tipo neurológico, gastrointestinal, cardiológico y respiratorio. El presente trabajo describe el tratamiento empleado principalmente en PNB durante este periodo. La coordinación de la succión-deglución-respiración es una de las habilidades más complejas a las que se enfrenta el PNB, debido a que presenta inmadurez anatomofuncional y una incorrecta integración sensoriomotriz para los altos requerimientos energéticos a los que debe someterse. La succión y deglución son procesos voluntarios e involuntarios que garantizan el paso seguro de alimentos de la boca al estómago, y requieren la coordinación de algunos pares craneales, del tronco y corteza cerebral y músculos de la boca, faringe y esófago. El tratamiento de rehabilitación consiste en el

Correspondence:

*Edda Aguilar-Vázquez

Email: tfeddaaguilar@ hotmail.com
Date of reception: 22-03-2017

Date of acceptance: 21-10-2017

DOI: 10.24875/BMHIME.M18000020
Available online: 12-07-2018 Bol Med Hosp Infant Mex. 2018;75:14-20 www.bmhim.com 
posicionamiento del niño y el cuidador al momento de la alimentación, la regulación de la sensibilidad y tono muscular perioral e intraoral, la coordinación lingual, el cierre labial, la regulación del flujo de leche, el control de la velocidad de las salvas y la adaptación de tetinas tanto para biberón como para seno materno. El procesamiento de la alimentación con el tratamiento se logró reducir a semana y media, mientras que en los PNB sin tratamiento, este proceso llegó a tomar hasta tres semanas.

Palabras clave: Succión. Deglución. Prematuridad. Ortodóncicas. Salvas. Amamantamiento.

\section{Introduction}

According to the World Health Organization, a child born with a gestational age of less than 37 weeks is considered a premature newborn (PNB) ${ }^{1}$.

The hospitalized premature newborn is usually surrounded by an unfavorable environment for its development, saturated with nociceptive and painful stimuli, the noise of monitors and ventilators, the intensity of light, the lack of gratifying tactile stimuli and physical isolation from the mother, which lead to difficulties for the adaptation of the child to the external environment ${ }^{2}$.

The effectiveness of a PBN to feed depends not only on the gestational age, but also on the muscle tone, the development of physiological stability, alertness, behavior, energy reserve, the maturity of the nervous system and the digestive tract, and of his medical condition.

At the central level, the brainstem has three basic reflexes that help to feed: rooting, sucking and swallowing. Two forms of suction are distinguished: the non-nutritive, immature and transitional, and the mature. These forms facilitate the motor and oral skills in the newborn.

During feeding, swallowing is a completely involuntary and reflexive process ${ }^{3}$. For this to develop properly, it is necessary to integrate a wide variety of structures involved in the process: bone, muscle (perioral, intraoral and pharyngeal) and nerve (cranial pairs V, VII, IX, $\mathrm{X}, \mathrm{XI}$, and $\mathrm{XII}$ ), which channel sensations and movements with swallowing ${ }^{4,5}$.

Swallowing consists of three phases, coordinated between them and breathing: oral phase, pharyngeal phase, and esophageal phase.

\section{Suction}

It is a rhythmic and coordinated movement of the tongue and mouth of the infant, which is triggered by introducing the nipple, finger or bottle inside the oral cavity.

\section{Evolution}

During prenatal development, olfaction and olfactory receptors are present from the $12^{\text {th }}$ week of gestation.
From this moment, a cerebral register of flavors and aromas of the amniotic fluid caused by its swallowing by the retro-nasal route exists. At the time of birth, the PNB can be able to recognize its his mother by her smell and start feeding with her colostrum.

Around week 20 of pregnancy, suction movements begin; in week 28, there is a higher record of aromas and flavors; in weeks 32 to 34 , suction, swallowing, and respiratory movements within the uterus (which do not constitute real respiration) are present in a coordinated manner $3,6-9$.

In humans, suction appears as a reflex from the prenatal stages, starting at week 18 of pregnancy, but its maturity is reached between $34-36$ week. At 32 weeks, the gag reflex is present, necessary as a defense in cases of fluid aspiration. Between weeks 34 and 35, the coordination between suction, swallowing and breathing and the uncoordinated movements of the tongue appear.

Suction is a reflex behavior that can be modified, and even intensified with learned references. It is determined by the maturational pattern of the central nervous system.

The classic notion of suction involves the formation of intraoral negative pressure. If there is an element with a hole in the mouth, the negative pressure extends to the object, and if it contains liquid, it will be transferred to the mouth ${ }^{9}$.

This conception implies that the PNB controls the amount of milk ingested. The efficiency of the suction depends on the pressure gradient obtained and the suctioning frequency ${ }^{3,6-9}$.

In the postnatal period, the mandible is still small, there is lingual protrusion towards the gums and lips, and the airspace determines the modality of breathing. At this time, there is adequate coordination, with an orientation towards the chest by identification. The most common difficulties in feeding PNB are related to the immaturity of the infant, as well as the lack of ability to rhythmically coordinate breathing with continued sucking and swallowing, conditioning a disorganized pattern. 


\section{Non-nutritive sucking}

It is the conditioning of suction stimuli unrelated to food; some functions are attributed to it, such as stress reduction, pain in the hospitalized newborn, promoting weight gain in PNB, maturation and gastrointestinal growth. Oxygen saturation improves when suckling the breast or pacifier if the non-nutritious suction was practiced before, since the newborn remains in a better condition and the maternal ability to breastfeed and produce milk is improved ${ }^{6}$. Mature non-nutritive sucking is accompanied by motor activity complexes of the esophagus, stomach, and small intestine. It is characterized by the presence of irregular sucking and short suckling episodes not associated with swallowing. When the process has ended, they return to a resting state or irregular sucking (movement of the lips). Over time, these bursts end swallowing and with the momentary inhibition of breathing.

In non-nutritive suction, the stimulation of the oral cavity leads to an increase in the vagal activity and can have several implications. The hormones involved in the absorption of food, such as gastric, insulin and glucose, rise as a result of increased vagal activity, which may explain the relationship between sucking the pacifier and weight gain, demonstrating that when infants use the pacifier during feeding by an orogastric tube, the formula has a faster transit. This suggests a higher efficacy in feeding, more significant weight gain and a better result in the Brazelton scale (maturational assessment), which indicates that the use of a pacifier can contribute to a more organized and adequate behavior for optimal feeding and better growth (decreased stress), allowing faster passage of the probe to complete oral feeding ${ }^{3,6,9}$.

Oxygen saturation improves when the breast or bottle is suctioned if a non-nutritive suction was previously performed, decreasing the in-hospital stay days compared with children who are not stimulated to a non-nutritive suction during feeding with an orogastric tube $e^{3,6,9}$.

\section{Nutritive sucking}

The nutritive sucking is related to food intake, either breast milk or formula. There are three different types of nutritive suction according to the physical conditions in which the PNB is found $d^{3,6-10}$.

\section{IMMATURE NUTRITIVE SUCKING}

It is observed in healthy PNB of less than 32.5 weeks of gestational age. The PNB performs three to five suction bursts with breaths and swallows that occur before and after the suction burst. The respiratory pause is equal in length to the short suction burst, with alternation of suction-swallowing and breathing in a coordinated manner, instead of the suction-swallow-breath coordination of 1:1:1 observed in full-term newborns. In this case, the PNB performs suction and breathing at the same time. The action of maintaining breathing during suction may be related to the child's instinct to protect the airway from fluid entrance ${ }^{9}$.

\section{TRANSITIONAL NUTRITIVE SUCKING}

Some PNBs and fragile full-term newborns (post-term older than 45 weeks of gestation) develop a disorganized pattern characterized by several suckling bursts (usually from 6 to 10), with equal duration pauses, and periods of apnea followed by a burst of longer suction. This pattern occurs when the child tries to use a mature pattern of continuous suction but does not have a smooth rhythm of suction-swallowing-breathing yet. Children who show more than one suction pattern (long and short sucking bursts during the same feeding period) are also considered transitional. Disorganized transitional suction is the most common pattern of feeding observed in children in the NICU and with the greatest potential for therapeutic intervention $n^{3,6-10}$.

Oxygenation and ventilation are related during nutritive suction since the airway closes briefly during each reflex suction. This obstruction is more significant during continuous suction than in intermittent suction and worsens with a nasogastric tube. Constant suction may show changes in blood chemistry that force the PNB to switch to an intermittent suction pattern.

The improvement of apnea during induced feeding (apnea by swallowing) is frequently associated with multiple swallows without breathing and usually correlates more with age (maturation) than with practice. Clinically, it means that the additional time to mature is of greater benefit than the frequent opportunities to "practice" oral feeding in premature infants. Term infants may show apneas by swallowing, but their presence is more frequent and prolonged in preterm infants who are reaching the corrected age compared to full-term infants ${ }^{9,10}$.

\section{Mature nUtRITIVE SUCKING}

It is related to food where the interval between each suction burst is one-second maximum. 
This suction pattern is typical of healthy term newborns. The mature pattern shows that there are continuous suction bursts ranging from 10 to 30 gentle suctions in a 1:1:1 ratio to the suction-swallowing-breathing rhythm; breathing appears continuous and uninterrupted and with small breathing pauses between suckling bursts, which are usually long at the beginning of the feeding process(continuous suction), followed by intermittent suctions with more opportunities to breathe while feeding continues ${ }^{9}$.

During nutritive sucking, newborns present the following patterns: inhale-swallow (rest)-spirit (ISS), exhale-swallow-inspire (ESI), known as type I; inspire-swallow-inspire (ISI) and exhale-swallow-exhale (ESE), known as type II; when there is breathing pause between two or more swallows, it is known as type III or with apneas due to multiple swallows (MSA) $)^{3,6-9}$.

In the process of expiration-suction-swallowing-breathing, the sequence of the different components is $1: 1$ (one suction for each swallowing and breathing) in neonates; the relationship can be 2 or 3:1:1 after six weeks of life.

The term newborn presents an E/S pattern characterized by sets of 20-30 suctions (at a rate of 1-2 per second), followed by pauses of 2-15 seconds, resulting in an average frequency of 55 suctions per minute, with variations between 18 and 100 suctions $^{3,6-9}$.

\section{Swallowing}

It is the act of feeding, whose principle is to consume a nutritious target. However, everyone agrees that food has a social character related to cohabitation, as well as the taste factor. The recent advances in technologies of the aerodigestive confluence, as well as research from the respiratory and digestive functions have shown a high incidence of disorders related to the swallowing function, to the point of constituting an obstacle for therapeutic, medication or reeducation processes. As a consequence, methods for the evaluation of dysphagia disorders emerge, as well as the improvement of re-education techniques, so it is important to update the concept of swallowing and its components ${ }^{9,11-13}$.

Currently, deglutition is understood as the propulsion action of the bolus exerted by the tongue towards the pharynx using the mylohyoid muscle.

To study swallowing, deglutition is divided into the following phases:

1) Oral phase. It is the preparation of the food bolus that includes intake and transportation. Begins with the neonate ability to use rhythmic and synchronic movements when the areola or the bottle contacts his lips, to squeeze the areola and milk ducts with his tongue, which forms a groove in its back helped by the jaw, which rises towards the palate rhythmicaIly. In this way, milk is transported by the tongue and directed to the posterior region of the mouth for swallowing, representing the end of the oral phase, which is considered the only voluntary stage of the swallowing process ${ }^{9,11,12,14}$. In the newborn or infant, the orbicularis of the lips plays a preponderant role in the coarctation of the lips over the nipple or pacifier. The suction and swallowing follow one another and are practically inseparable. The intra-oral vacuum is achieved through the tongue, and thanks to the suprahyoid muscles, the stability of the floor of the mouth is achieved. The peristaltic waves lead the oral content towards the oropharynx; the search and suction reflexes govern this feeding mode. The PNB does not breathe when swallowing, contrary to what could be assumed because of the high position of the larynx in the neck, considering the oral phase of normal swallowing until six years old. The essential key for the oral stage is that the newborn has the desire to eat, as well as the ability to close the lips and position the tongue and bolus to move on to the next stage $\mathrm{e}^{9,11,12,14}$.

2) Pharyngeal phase. It is the second stage that starts with the swallowing reflex (complex mechanism essential for the safety of the respiratory tract). It occurs when there is enough milk in the oral cavity: the liquid is pushed back when the tongue contracts and goes up towards the palate forcing it towards the orophary$\mathrm{nx}$. This process stimulates the sensory corpuscles in the fauces and the pharyngeal wall ${ }^{9,11,12,15}$. At this stage, sensory information is extremely important so that swallowing is effective and correct; it materializes through sensory receptors (movement, pain, temperature, taste, smell, chemical and proprioceptive), which send the information to the medulla oblongata from which numerous motor responses of the cranial nerves to the oropharyngeal muscles emerge. The larynx elevates, there is a vocal cord closure to protect the airway, the muscles of the pharynx make a wave motion to send the fluid into the esophagus and thus favor the closure of the epiglottis. The larynx is also protected by arytenoid cartilage and false and true vocal cords, which prevents the milk from returning to the mouth or going to the nasal passages or in the airway. Due to this safety mechanism, the reduction of ventilation is diminished. Newborn has shorter inspirations and his respiratory rate decreases. The swallowing 
lasts a second and its recovery is given by breaks that the newborn performs ${ }^{9,11,12,14}$.

3)Esophageal phase. The passage from the pharyngeal phase, also called reflex, to the esophageal phase is effective only when food leaves the pharynx and enters the upper sphincter of the esophagus, initiating the last stage of swallowing that is completely automatic. The opening of the upper sphincter of the esophagus is possible thanks to the radial attraction exerted by food together with the decrease in the pressure of the sphincter tone and the traction induced by the elevation of the larynx. After the passage of the food bolus, the sphincter pressure increases significantly, preventing reflux. The arrival of food in the stomach puts an end to this phase.

\section{Rehabilitation treatment}

In conjunction with the review of international literature, it has been observed that patients treated on time, manage to have a satisfactory feeding process in a period of one week or a week and a half; however, children who, for various reasons, do not receive treatment on time, take around three weeks to achieve an adequate feeding process.

\section{Positioning}

Within the proper management of suction-swallowing-breathing alterations, there is evidence that many conditions and improvements in the triad can be treated with an adequate positioning of the head concerning the trunk. Although it is larger and heavier concerning the chest, it is essential that the head is aligned during the feeding process. This alignment is achieved by holding the child's head at the base of the skull with the index finger and thumb and the rest of the hand between the clavicles and scapulae to support it. The baby should be placed on the legs of the mother or the therapist in charge. With this position, it is possible to keep the head aligned and slightly raised to allow safe passage of the liquid through the oropharynx, mainly when the child has palatal vein dysfunction or respiratory alterations that cause oxygen desaturation and fatigue $e^{2,9,11,15-18}$.

Although the child is breast fed, it is crucial to guide the mother in the proper posture to favor the safe feeding of PNB once they have managed to avoid respiratory complications.

\section{Sensitivity and muscle tone}

We must integrate the search reflex, which is a fundamental part of the beginning of suction both from the bottle and from the mother's womb. The way we perform the stimulation for the search reflex is by a firm and continuous patting around the lips. First it will cause the child to half-open the mouth, trying to reach the finger with which we are stimulating and, later, pucker the lips and tighten them during the time the stimulus continues. If the goal is to improve muscle tone, the pulsations should continue towards the cheeks.

If the PNB presents low muscle tone during suction, a massage can be performed, sliding the index and thumb fingers from the earlobe to the labial corner of the lips, applying some pressure. Later, with the same fingers, make a vibratory pressure from the earlobes to the corner of the mouth. In this way, the increase in muscle tone is favored so that the PNB exerts a greater force when performing both the lip-seal and the pressure during suction $2,7,9,14,15,18-20$.

If the PNB has good muscle tone, the same exercises will be performed, but in the opposite direction; that is, from the corner of the lips to the earlobes, firmly and continuously. A circular massage on the cheeks is also applied inside the mouth, sliding the index finger from the corner of the lips towards the cheeks.

In some PNB thermal stimulation can be used using a cold pacifier. Also, a medicine dispenser with $10 \mathrm{ml}$ of cold milk and $10 \mathrm{ml}$ of warm milk can be used, so that thermal contrast improves alterations in sensitivity $2,7,9,14,15,18-20$.

\section{Lingual coordination}

PNB motions when sucking are from bottom to top and from front to back. These motions are altered by the front or back projection of the tongue, caused by intubation or placement of an orogastric tube and by alterations in muscle tone at the axial level. These changes can be corrected by performing a sweep with the index finger or little finger on the tongue of the PNB, as far back as possible without causing a gag reflex, and sliding the finger making pressure to the tip of the tongue. Also, at the moment of offering the bottle, exert pressure against the palate with the nipple of the bottle so that the tongue is lowered and placed in the proper position for suction.

Once the proper position of the tongue is achieved, it is important to stimulate the movement while feeding the 
PNB with the bottle, and thus continue to establish feedback on the proper movement of the tongue $e^{2,9,11,14-18}$.

It is also important to work the slow and sustained mobilizations of upper limbs and decrease the axial tone if it is increased since it is also a conditioning factor for the retropulsion of the tongue.

\section{Lip closure}

While suckling, an adequate lip closure has the objective of avoiding fatigue during the feeding process. This will promote the strength and position with which the tongue performs the compression the nipple. By having an adequate lip-seal closure, there will be less spillage of milk. Therefore, it is important to work with the appropriate and ideal techniques so that the lip-seal is adequate.

The mandibular support is made with the middle and ring finger of the hand with which the bottle is held. By this support, the child is helped to close his mouth better when sucking and to evade air intake or the phasic bite persistence. This support is applied in children with low muscle tone and with increased tone $\mathrm{e}^{2,7-9,14,15,18-20}$.

If support is necessary, the cheek support is applied slightly below the corner of the lips, which allows the pressure made by the Bichat bags to be more effective for the pressure the child requires along with the tongue movement.

In some cases, where hypotonia is considerable, both the cheek support and the mandible are required. In this case, it should be supported with the hand with which the head of the PBN is held, and one of the cheeks is pressed with the thumb. With the hand with which the bottle is held, support is made in the jaw and the other cheek. This technique is of essential support for children with Down syndrome, premature babies who are just beginning their oral feeding and who have respiratory problems. It is important that this technique is done every time the PNB is fed mainly with the bottle. Once an adequate suction is achieved, it will be possible to start feeding to the mother's breast, where the mandibular support and cheek support is minimal2,7-9,14,15,18-20.

\section{Regulation of milk flow}

Another situation that can cause problems at the time of feeding the baby is the flow of milk; that is, the amount of milk that comes from the bottle and, in some cases, from the mother's breast.

In the case of the bottle, if it is not possible to change the teat and it has a fairly large hole, we should help regulate the flow by keeping the bottle at 90 degrees concerning the child's face. In this way, despite the slightly increased intake of air, it is favored that the baby performs the sucking bursts with greater force and avoids the sensation of drowning due to excess fluid.

In the case that the mother produces too much milk, it is recommended to feed the baby while sitting, previously extracting a little milk.

\section{Speed control}

Many children can present a marked speed at the time of performing the sucking bursts, which causes problems such as fatigue, choking and respiratory distress.

The appropriate way to help the child control the speed, apart from improving muscle tone and strength, is to pull the bottle slightly outward at the time of feeding so that the child makes the deepest and slowest bursts. In this way, the child is fed at a better pace, avoids choking and eludes breathing difficulties $2,7-9,14,15,18-20$.

\section{Proper selection of bottle nipple}

Among the factors to consider when feeding a baby is the type of nipple for the bottle. Because of this, after assessing the type of suction, rhythm, force, and speed, we must assess whether we should use a conventional nipple, an orthodontic nipple or special nipple for PNB (longer and softer).

If the baby is breastfed and the mother's nipple is not well formed to achieve adequate suction, a nipple shield should be used to favor the formation of the nipple, since the child will have less difficulty to be fed.

Unfortunately, in Mexico, there is little variety of nipples for the bottle. It is important to indicate that it is essential that the bottle nipple resemble as much as possible a real nipple. Therefore, bottles that have flat and very long teats or very hard silicone are not recommended since they will represent a greater difficulty for the child, whatever the condition that is causing problems $^{2,7-9,14,15,18-20}$.

\section{Conclusions}

The purpose of this work was to present the experience in the Department of Rehabilitation of the Hospital Infantil de México Federico Gómez in the management of eating disorders in the PNB over 20 years, which, based on various international bibliographies, 
has allowed to offer the most appropriate treatment for PNB.

However, it is very important to bear in mind that PNB, apart from the neurological immaturity, may have some additional pathology such as cardiac, respiratory or gastrointestinal, which will significantly affect the suction-swallowing-breathing triad. This factor must be taken into account to avoid fatigue or significant loss of weight gain $2,9,11,14,15$.

\section{Conflicts of interest}

The authors declare no conflicts of interest.

\section{References}

1. Espinosa J, Arrollo MO, Martín P, Ruíz D, Moreno J. Guía Esencial de Rehabilitación Infantil. Madrid: Editorial Médica Panamericana; 2012. pp. 37-61.

2. Díaz R. Lactancia materna en el bebé prematuro hospitalizado en la Unidad de Cuidados Intensivos Neonatales (Segunda Entrega). Disfagia al día; 2012. Available at: www.disfagiaaldia.com

3. Rendón Macías ME, Serrano Meneses GJ. Fisiología de la succión nutricia en recién nacidos y lactantes. Bol Med Hosp Infant Mex. 2011; 68:319-27.

4. Moore KL, Dalley AF, Agur AMR. Anatomía con Orientación Clínica. Querétaro: Editorial Médica Panamericana; 2007.

5. Sadler TW. Langman. Embriología Médica. Buenos Aires: Editorial Panamericana; 1993.
6. Guido-Campuzano MA, Ibarra-Reyes MP, Mateos-Ortiz C, Mendoza-Vásquez N. Eficacia de la succión no nutritiva en recién nacidos pretérmino. Perinatol Reprod Hum. 2012;26:198-207.

7. Lau C. Oral feeding the preterm infant. NeoReviews. 2006;7:19-27.

8. Senn TE, Espy KA. Effects of neurobehavioral assessment on feeding and weight gain in preterm neonates. J Dev Behav Pediatr. 2013;24:85-8.

9. Dailey K. Pediatric dysphagia resource guide. Sanford: Editorial Singular Thomson Learning; 2001.

10. Inostroza E, Leal I, Neira S, Pérez G, Villareal K. Descripción de los reflejos orofaciales, succión nutritiva y no nutritiva en lactantes prematuros y recién nacidos de término. Repositorio Académico de la Universidad de Chile; 2013. Available at: http://www.repositorio.uchile.cl/handle/2250/116726.

11. Bragelien R, W Rokke, Markestad T. Stimulation of sucking and swallowing to promote oral feeding in premature infants. Acta Paediatr. 2007; 96:1430-2.

12. Medoff- Cooper B, McGrath J, Shults J. Feeding patterns of full-term and preterm infants at forty weeks postconceptional age. J Dev Behav Pediatr. 2002;23:231-6.

13. Burklow K, McGrath A, Kaul A. Management and prevention of feeding problems in young children with prematurity and very low birth weight. Infants and Young Children. 2002;14:19-30.

14. Ross ES, Browne JV. Developmental progression of feeding skills: an approach to supporting feeding in preterm infants. Semin Neonatol. 2002; 7:469-75.

15. Boiron M, Da Nobrega L, Roux S, Henrot A, Saliba E. Effects of oral stimulation and oral support on nonnutritive sucking and feeding performance in preterm infants. Dev Med Child Neurol. 2007;49:439-44.

16. Thomas JA. Guidelines for bottle feeding your premature baby. Adv Neonatal Care. 2007;7:311-8.

17. Pridham K, Saxe R, Limbo R. Feeding issues for mothers of very-lowbirth-weight, premature infants through the first year. J Perinat Neonatal Nurs. 2004;18:161-9.

18. Fucile S, Gisel E, Lau C. Oral stimulation accelerates the transition from tube to oral feeding in preterm infants. J Pediatr. 2002;141:230-6.

19. Medoff-Cooper B. Nutritive sucking research from clinical questions to research answers. J Perinatal Neonatal Nurs. 2005;19:265-72.

20. Field T. Stimulation of preterm infants. Pediatr Rev. 2003;24:4-12. 